\title{
Metabolic syndrome in aircrew: flight safety implications and aptitude management
}

\begin{abstract}
The metabolic syndrome (MetS) is one of the major public health problems worldwide, the prevalence of MetS increases continuously and aircrew are not spared from this high prevalence. The aim of this paper is to explain what the implication of metabolic syndrome in flight safety is and how to manage the aircrew's aptitude having this disease.

The ultimate importance of MetS is to help identifying persons with high risk of type 2 diabetes and cardiovascular disease, especially aircrew member who must be free from diseases or disabilities which may cause inflight incapacitation. Therefore, the MetS have many specific aspects in aerospace medicine. In flight, MetS can cause sudden or subtle incapacitation by the occurrence of acute myocardial infaction, stroke or by a sudden death. These complications can be decompensated by altitude and flight conditions including altitude hypoxia, stress and $+\mathrm{Gz}$ acceleration of fighter pilot in a high performance aircraft. In aircrew, diabetes may have an impact on the flight safety through its complications (occular, cardiovascular, stroke, etc), and through the glycaemic desorder which may cause hypoglycemia in flight. Finally, flight surgeons or squadron medical officers conducting periodic medical examination of aircrew could play a proactive role in identifying MetSaffected aircrew and advocating their lifestyle modifications to maintain stronger physical standards for optimal performance in their operational roles.
\end{abstract}

Keywords: metabolic syndrome, flight safety, aeromedical fitness, flight incapacitation
Volume 5 Issue I - 2017

\author{
Meryem Zerrik, Houda Echchachoui, Zakaria \\ lloughmane, Mohamed Chemsi \\ Aeromedical Expertise Center of the Instruction Military Hospital \\ Mohamed V, University Mohamed V, Morocco
}

\begin{abstract}
Correspondence: : Meryem Zerrik, School of Medicine and Pharmacy, University Mohamed V- Rabat, Morocco, Tel 002 I266 I74 I I38, Fax 002 I25377/5 I37, Email meryemdoc08@gmail.com
\end{abstract}

Received: May 08, 2017 | Published: July II, 2017
Abbreviations: MetS, metabolic syndrome; WHO, world health organization; EGIR, european group for the study of insulin resistance; NCEP ATP II, national cholesterol education programthird adult treatment panel; IDF, international diabetes federation; CVD, cardiovascular disease

\section{Introduction}

The metabolic syndrome (MetS) is one of the major public health problems worldwide, ${ }^{1}$ the prevalence of MetS are continuously increasing and aircrews are not spared from this high prevalence. The aim of this paper is to explain what the implication of metabolic syndrome in flight safety is and how to manage the aircrew's aptitude having this disease.

\section{Discussion}

The prevalence of MetS in general population referring to the French DESIR study is about $16 \%$ in males and $11 \%$ in females. ${ }^{2}$ Many definitions for the MetS exist: World Health Organization (WHO), European Group for the Study of Insulin Resistance (EGIR), National Cholesterol Education Program-Third Adult Treatment Panel (NCEP ATP II), International Diabetes Federation (IDF). According to the IDF definition 2005, for an individual to be diagnosed as having the MetS, he must have central obesity (abnormal waist circumference: for Europid males is $\geq 94 \mathrm{~cm}$ and for Europid females is $\geq 80 \mathrm{~cm})^{3}$ plus two of these four additional factors (Raised triglycerides, Reduced HDLcholesterol, Raised blood pressure, Raised fasting plasma glucose). ${ }^{3}$

Pathogenesis of the MetS is complex and not entirely elucidated; insulin resistance and abnormal fat distribution (central obesity) are two features with potential causative factors. ${ }^{4}$ Other factors have also been implicated in the development of the MetS, including genetic profile, physical inactivity, ageing, a proinflammatory state and hormonal dysregulation. ${ }^{5}$ It has been suggested that the role of these causal factors may vary depending on ethnic group and are related to lifestyle changes. ${ }^{6}$

The ultimate importance of MetS is to help identifying persons with high risk of both type 2 diabetes and cardiovascular disease (CVD), ${ }^{3}$ especially aircrew member who must be free from diseases or disabilities which may cause inflight incapacitation. Therefore, the MetS have many specific aspects in aerospace medicine. Its prevalence in aircrew members was 18\% among Royal Jordanian Air Force pilots ${ }^{7}$ while it was $9.9 \%$ among Republic of Korea Air Force ${ }^{8}$ using NCEP ATP III criteria. The relatively low prevalence of MetS is supported by different factors: young age, higher socio-economic status $^{9}$ and their periodic medical examination.

\section{MetS and flight safety implications}

The presence of the MetS is associated with a significant increase in cardiovascular mortality ( $12 \%$ vs. $2 \%)^{10}$ and all-cause of mortality, ${ }^{11}$ it's also associated with a high risk of cardiovascular disease (CVD). In flight MetS can cause sudden or subtle incapacitation by the occurrence of acute myocardial infaction, stroke or by a sudden death. ${ }^{12}$ These complications can be decompensated by altitude and flight conditions including altitude hypoxia, stress and $+\mathrm{Gz}$ acceleration in fighter pilot in a high performance aircraft. Non-diabetic people with the MetS are at a very high risk for developing type 2 diabetes, the risk for diabetes is up to fivefold higher in patients with the syndrome. ${ }^{11}$ In aircrew member, diabete may have an impact on the flight safety through its complications (occular, cardiovascular, stroke, etc), and through the glycaemic desorder which may cause hypoglycemia in flight. ${ }^{13}$ Obesity is rising rapidly in many parts of the world, ${ }^{14}$ and the high prevalence of the MetS is mainly related to the obesity epidemic. ${ }^{5}$ Obesity contributes to hypertension, hyperglycaemia, low HDLcholesterol, high serum TGs, and insulin resistance and it's associated 
with higher CVD risk. ${ }^{5}$ Overweight and obesity are both a problem in aviation medicine because they may endanger flight safety directly during ejection or depressurized flight, or indirectly by increasing the other CVD already described. Fighter pilot is exposed to specific constraints like those of ejection seat, cockpit ergonomic and the need of physical strength. ${ }^{15}$

MetS can be associated with sleep apnea syndrome, it's a frequent pathology that does not spare aircrew, ${ }^{16}$ its consequences such as excessive daytime sleepiness and increased cardiovascular risk are a major risk to aviation safety and requires a systematic research in people with high-risk to have obstructive sleep apnea syndrome. ${ }^{16}$

\section{Aptitude management}

Military and civilian aircrew is held to stringent physical standards in order to be considered qualified for flight. While MetS itself can be a medical condition which causes flight disqualification if it's associated with another cardiovascular disease like hypertension, diabetes, coronary disease or sleep apnea syndrome. The aeromedical fitness can be reconsidered by derogation if the disease is stabilized and the medical therapeutic have no risk for aeronautical activity (no anticoagulant drug, anti-ischemic drugs, self-made hypoglycemic therapy, insulin etc.).

\section{Conclusion}

Finally, flight surgeons or squadron medical officers conducting periodic medical examination of aircrew could play a proactive role in identifying aircrew affected by MetS and advocating their lifestyle modifications to maintain stronger physical standards for optimal performance in their operational roles.

\section{Acknowledgments}

None.

\section{Conflicts of interest}

The authors declare that there is no conflict of interest.

\section{References}

1. Zimmet P, Magliano D, Matsuzawa Y, et al. The metabolic syndrome: a global public health problem and a new definition. J Atheroscler Thromb. 2005;12(6):295-300

2. Balkau B, Vernay M, Mhamdi L, et al. The incidence and persistence of the NCEP (National Cholesterol Education Program) metabolic syndrome. The French D.E.S.I.R. study. Diabetes Metab. 2003;28(5):364-376.
3. Alberti KG, Zimmet P, Shaw J. Metabolic syndrome-a new worldwide definition. A Consensus Statement from the International Diabetes Federation. Diabet Med. 2006;23(5):469-480.

4. Reaven GM. Role of insulin resistance in human disease (syndrome X): an expanded definition. Annu Rev Med. 1993;44:121-131.

5. Saad MF, Lillioja S, Nyomba BL, et al. Racial Differences in the Relation between Blood Pressure and Insulin Resistance. N Engl J Med. 1991;324(11):733-739.

6. Eckel RH, Grundy SM, Zimmet PZ. The metabolic syndrome. Lancet. 2005;365(9468):1415-1428.

7. Khazale NS, Haddad F. Prevalence and characteristics of metabolic syndrome in 111 Royal Jordanian Air Force pilots. Aviat Space Environ Med. 2007;78(10):968-972.

8. Rhee C, Kim J, Kim JY, et al. Clinical markers associated with metabolic syndrome among military aviators. Aerosp Med Hum Perform. 2015;86(11):970-975.

9. Beinhocker ED, Farrell D, Zainulbhai AS. Tracking the growth of India's middle class. The McKinsey Quarterly. 2017;3:51-61.

10. Isomaa B, AlmgrenP, Tuomi T, et al. Cardiovascular Morbidity and Mortality Associated With the Metabolic Syndrome. Diabetes Care. 2001;24(4):683-689.

11. Stern MP, Williams K, González-Villalpando C, et al. Does the metabolic syndrome improve identification of individuals at risk of type 2 diabetes and/or cardiovascular disease? Diabetes Care. 2004;27(11):2676-2681.

12. Brocq FX, Deroche J, Chemsi M, et al. Management of metabolic syndrome by the aeromedical examiner. Med Aero Spat. 2009;50:19-25.

13. Deroche J, Paris JF, Perrier E, et al. Management of a diabetes mellitus in the private pilot fitness assessment. Med Aero Spat. 2004;45:6-10.

14. Visscher TL, Seidell JC. The public health impact of obesity. Annu Rev Public Health. 2001;22:355-375.

15. Zerrik M, Echchachoui H, Moumen A, et al. Obesity in fighter pilots: impact on flight savety and management by the physician expert in Morocco. Med Aero spat. 2015;56:75-81.

16. Dubourdieu D, Brocq FX, Bisconte S, et al. The medical evaluation of sleep apnea syndrome in aeronautical expertise. Med Aero spat. 2010;51:7-15. 